\title{
Historia y música. Comentarios sobre Una historia de la música colonial hispanoamericana de Leonardo Waisman
}

\author{
por \\ Juliana Pérez González \\ Investigadora independiente \\ Julianabe@usp.br
}

\begin{abstract}
Después del declive de los grandes relatos en la historiografía, llama inmediatamente la atención el título Una historia de la música colonial hispanoamericana, reciente libro del musicólogo argentino Leonardo Waisman. En principio, el encabezado vincula la publicación de 480 páginas con una tradición académica que parecía abandonada en nuestro campo y que sirve para encarar interpretaciones de amplio espectro territorial o cronológico. Como es mencionado por su autor, para el período colonial solamente se contaba con un capítulo escrito por Robert Stevenson para el segundo volumen de la colección The Cambridge History of Latin America (1984) y un borrador de Samuel Claro (1985), preservado en la biblioteca de la Pontificia Universidad Católica de Chile. En fecha más reciente, se sumaron el libro Música colonial hispanoamericana (2016), del músico argentino Ramiro Albino -texto de divulgación científica-, y el trabajo mencionado. Si bien es cierto que, en las últimas décadas, la microhistoria y los estudios de caso permitieron avanzar en el conocimiento dentro del campo de la historia de la música colonial en este continente, en contraste, pedidos por análisis con mayor amplitud cronológica o territorial se oían por los corredores. A medida que más estudios de caso han salido a la luz, se ha vuelto cada vez más urgente estudiar también las conexiones o relaciones que hubo a lo largo del continente y con España ${ }^{1}$. En este sentido, los grandes relatos parecen ser el género ideal para pensar el fenómeno musical en amplias unidades de territorio y tiempo.

Partiendo de esa constatación, me permito comentar la última publicación de Leonardo Waisman, editada por Gourmet Musical Ediciones el año pasado (2018) en Buenos Aires, Argentina. Su aparición es interesante porque, adicional al carácter general sugerido en el título, su autor es un especialista de amplia trayectoria y reconocimiento en el tema que escribe. Músico, con estudios doctorales en historia de la música en la Universidad de Chicago, Waisman ha centrado su vida académica en la música de los siglos XVI, XVII y XVIII tanto americana como europea; también ha aportado a la reflexión musicológica con análisis del quehacer disciplinario; ha participado en la elaboración de diversos catálogos musicales; ha sido transcriptor y editor de partituras, y se ha desempeñado como intérprete en el clavecín y dirección coral.
\end{abstract}

1 La publicación reciente Músicas coloniales a debate. Procesos de intercambio euroamericanos intenta responder a esta necesidad. Ver Marín López 2018: 17-22.

Revista Musical Chilena, Año LXXIII, julio-diciembre, 2019, Nº 232, pp. 138-146 
El libro que comentaré también fue alimentado por el trabajo del grupo de investigación en musicología histórica del Centro de Producción e Investigación en Arte (CePIA), adscrito a la Facultad de Artes de la Universidad Nacional de Córdoba (UNC). Según se explica, este texto fue elaborado en el marco de dos proyectos individuales de su autor principal, como investigador del Conicet, y de tres proyectos colectivos, "encarados" por el grupo de investigación entre 2010 y 2013 (Waisman 2018: 18). Muy probablemente de esos proyectos surgió su apéndice de cerca de 100 páginas, "Compositores activos en Hispanoamérica, ca. 1550- ca. 1808”, elaborado por Lucas Reccitelli, actual estudiante de doctorado, y Luciana Giron Sheridan, alumna del Departamento de Música de la UNC.

La lectura de Una historia de la música colonial hispanoamericana plantea reflexiones que sobrepasan los límites de una reseña convencional. En virtud de ello, a continuación pretendo comentar la publicación enfatizando en puntos neurálgicos de la intersección entre historia y música, propios de la historiografía musical. Sin ser especialista en el repertorio colonial, este texto surge de mi lectura atenta desde el oficio del historiador de la música.

En primer lugar, aunque el título parezca sugerirlo, no estamos ante un relato integrador, como el mismo Leonardo Waisman advierte en la introducción. Las tres partes que conforman la obra no construyen un argumento vertebral que le otorgue unidad". Se trata de un libro fragmentario que "intenta sugerir el todo a partir de la presentación de algunos trozos (Waisman 2018: 11)”. En la introducción se advierte que su fragmentación tiene raíces en la propia división del conocimiento histórico-musical del período colonial y del territorio hispanoamericano, impresión que se desprende, justamente, de la proliferación de estudios de caso ya mencionada.

Efectivamente este trabajo no se caracteriza por ultrapasar los límites político-administrativos y pensar Hispanoamérica como unidad, sino trata la información según la organización geopolítica impuesta por la metrópolis. Los subcapítulos reflejan una suma de núcleos poblacionales y no abordan análisis comparativos entre localidades en condiciones similares. Además, la selección de información terminó por excluir resultados de investigaciones recientes que muestran interesantes matices en lugares de menor protagonismo para la historiografía anterior, como los actuales territorios de Chile y Colombia ${ }^{3}$.

La obra también está fraccionada por otro vector, además del geográfico. Ella calca en su escritura la pretendida división en grupos raciales o castas de la sociedad hispanoamericana. Es decir, la división instaurada en el siglo XVI en república de indios y república de españoles se refleja en separar capítulos acerca de la actividad musical de catedrales y ciudades (república española), de capítulos respecto de la música en las reducciones, parroquias y doctrinas (república de indios). Con todo, el autor no ahorra esfuerzos en señalar que existieron múltiples formas de eludir esta separación y que el proyecto de segregación rápidamente fracasó. Tal fracaso también se reflejó en la organización del libro, pues se incluyeron capítulos "híbridos" dedicados a fiestas públicas, música doméstica, cofradías, conventos, monasterios y teatros, ámbitos donde parece que primaban, justamente, los entrecruzamientos entre las castas. En estos apartados se aprecia con mayor facilidad las complejidades de una sociedad en proceso de mestizaje y movida por luchas sociales y étnicas.

Las varias divisiones que cruzan la publicación facilitan la lectura aleatoria de los capítulos, como el mismo autor sugiere. Bien sea por la propuesta osada o por haber concebido sus partes en momentos diferentes -como veremos-, la lectura secuencial deja la impresión de cierta desorganización, tangible en repeticiones innecesarias, eventuales contradicciones y generalizaciones ${ }^{4}$. Por ejemplo, se menciona que entre los siglos XVI y XVIII los españoles reclutaron alumnos de música

2 Incluso, previamente se contempló que el título fuera "La música colonial hispanoamericana: una historia en tres capítulos y tres enfoques", como aparece en el curriculum vitae del autor, en el momento de mi consulta. Waisman s//d.

3 Vale mencionar la producción de Alejandro Vera del territorio chileno, considerado habitualmente periférico, y los recientes artículos de Egberto Bermúdez en el siglo XVI en actual territorio colombiano.

4 Por ejemplo, una misma cita en pp. 130 y 252, y mismo párrafo en pp. 63 y 249. 
entre los hijos de la nobleza indígena y que estos fueron eximidos de regímenes de trabajo forzado y tributos (Waisman 2018: 63, 67, 249). Sin embargo, se cita un documento mexicano explicando que los músicos indígenas de cierto convento debían pagar tributo (Waisman 2018: 64). En realidad, casos particulares a lo largo del continente sugieren que la exoneración tributaria de músicos indígenas estuvo lejos de ser una generalidad y que, por el contrario, fue un continuo campo de disputa con innúmeras variables.

Cada una de las tres partes del libro está dedicada a uno de los siglos del período. La organización general en centurias merece un comentario, pues ella no se desprende enteramente del objeto de estudio. El libro comienza con el reinado de Felipe II porque en ese momento "se fundaron y difundieron las instituciones y modos de acción que servirían de base para las prácticas musicales de los dos siglos siguientes (Waisman 2018: 13)", y llega hasta el año de 1808, fecha "meramente conveniente" pues podría haberse adentrado más en el siglo XIX "sin encontrar cambios de fondo (Waisman 2018: 14)". Si los cambios de siglo no necesariamente implicaron puntos de quiebre en la actividad musical, entonces, ¿por qué insistir en esa división cronológica?

Como revela el autor, las partes inicial y final de la obra son reediciones de textos publicados anteriormente. La primera parte fue escrita en 2000 y publicada en 2004 como capítulo final del libro Políticas y prácticas musicales en el mundo de Felipe II. La segunda parte es la más inédita y está dedicada al análisis musical y al siglo XVII, un siglo considerado un "período de transición sin personalidad propia (Waisman 2018: 99)". Ya la tercera parte se ocupa del siglo XVIII, entendido como un período de modernización por la llegada del estilo italiano. Esta última fue redactada en 2009 para el volumen 4 de Historia de la música en España e Hispanoamérica, volumen dedicado al siglo XVIII y que fue publicado en 2014. Por tanto, a juzgar por la génesis de las partes del libro, la división cronológica en tres siglos fue resultado de las coyunturas editoriales en que nacieron, y no de una reflexión musicológica propiamente dicha.

Ahora bien, las versiones publicadas en aquellos libros españoles en 2000 y 2009 explican el caso hispanoamericano a la musicología española, principalmente, y reflejan el estado del arte en esos años. A causa de la distancia temporal entre esos capítulos y el libro aquí comentado, comparé sus dos versiones en busca de transformaciones. En suma, la obra comentada respetó la mayor parte del contenido de sus partes originales ${ }^{5}$. Se agregaron algunos datos a lo largo del texto y pequeños apartados dedicados a las catedrales de Cuba y Santo Domingo, de Lima, La Plata y Santiago del Estero, así como informaciones acerca del funcionamiento de conventos y cofradías en el siglo XVIII, entre otros asuntos. Lejos de dudar de la relevancia de los aportes incorporados, llama la atención que los argumentos principales no sufrieran modificaciones considerables. Las informaciones nuevas sirvieron para detallar o ampliar aspectos esbozados brevemente en los textos originales, sin dar lugar a diferencias interpretativas.

Vale detallar que la primera parte se alimentó con informaciones disponibles en artículos de Egberto Bermúdez (2001) ${ }^{6}$, María Gembero Ustárroz (2002 y 2007), Omar Morales Abril (2006 y 2007), Marisa Restiffo (2011); en libros de Javier Suárez Pajares (1998) y Josefina Muriel y Luis Lledías (2009), así como en las importantes tesis doctorales de Bernado Illari (2001), Javier Marín (2007) y Kydalla Etheyo Young (2010). Por su lado, la tercera parte del libro fue enriquecida con datos de artículos de Morales (2008), Bermúdez (2010), Montserrat Capelán Fernández (2013), Luis Rodríguez Toledo (2013), y libros de David Coirman Michailos (2010) y Kristin Dutcher Mann (2010). El autor también incluyó informaciones de la colección de 5 volúmenes Ritual Sonoro Catedralicio, editada en México. En particular fueron citados textos de Lidia Gómez García, Juan Manuel Yáñez García, Gustavo Mauleón Rodríguez, Aurelio Tello, Lérida Moya Marcos y Ryszard Rodys (Tomo I, dedicado

5 Eventualmente modificó el orden de párrafos; reutilizó apartados en la introducción del libro y en la segunda parte borró apenas frases; citó un par de cronistas más; aumentó el número de compases de algunos ejemplos musicales, y cambió partituras para ilustrar ciertos postulados.

${ }^{6}$ Las referencias bibliográficas mencionadas en este párrafo se detallan en el libro de Waisman y se omiten en la bibliografía final del presente documento. 
a catedrales y parroquias); de Celina Becerra Jiménez, Cristóbal Durán Moncada, Violenta Paulina Carvajal Ávila (Tomo II, respecto de enseñanza), y de Galia Greta Hernández Rivero y Lidia Gómez García (Tomo V, centrado en el caso de Puebla).

Entre los apartados más novedosos e interesantes de esta publicación, pese a su lenguaje hermético para los no músicos, están los capítulos dedicados al villancico y la chanzoneta, de la segunda parte. Aunque fracciones de los análisis musicales hayan sido esbozados en el texto de la Historia de la música en España e Hispanoamérica, aquí adquieren una nueva dimensión al ser pensados bajo la teoría musical de la época. Waisman se sirve de teóricos musicales como Tomás de Santa María (1565) y Pablo Nassarre (1723) para señalar el manejo que se hacía de la música modal, eventuales tránsitos hacia la armonía tonal y la combinación de las dos teorías (Waisman 2018: 182). Esto lo demuestra analizando minuciosamente obras de Gaspar Fernández (1563/71-1629), Juan Gutiérrez de Padilla (1590-1664), Tomás de Torrejón y Velasco (1644-1728) y Juan de Araujo (1649-1712), cuatro compositores representativos de momentos distintos. El autor aclara que fue más difundido el tratado de Pietro Cerone, Melopeo y maestro (1613) pero que este no fue aplicado por los compositores (Waisman 2018: 182). Queda la duda de cuáles teóricos musicales eran conocidos en Hispanoamérica y si se puede establecer una relación más estrecha entre sus tratados, la enseñanza musical y el lenguaje de los compositores del continente. De todas formas, la aproximación analítica desarrollada en el libro auxilia a músicos interesados en la comprensión de los elementos constitutivos de este repertorio y enriquece el debate musicológico respecto de las particularidades del lenguaje musical de aquel entonces.

Además, el análisis musical propone hipótesis interesantes que no dejan de ser polémicas. Por ejemplo, se considera que Gaspar Fernández incorporó "elementos afroamericanos auténticos" en una de sus piezas y se le adjudican intereses "protoetnomusicológicos". Además, se asegura que tal epíteto "se ve reforzado por la coherencia con que [Fernandez] musicaliza" dos textos náhuatl usando "figuración yámbica con acentuación en la primera sílaba (Waisman 2018: 94-95)". Es una pena no haber profundizado en este postulado -inclusive para quien encontró exagerado acudir al anacronismo-. Para fortalecer la hipótesis era necesario enunciar brevemente las características de la música indígena mexicana y, luego, deducir que el ritmo yámbico usado por Fernández era realmente reflejo de tal tradición. Mayor cuidado argumentativo se observa al indicar que complejos ritmos aditivos, atribuidos frecuentemente a las tradiciones africanas, también estaban presentes en la música europea y que, por tanto, su uso en la música colonial no refleja necesariamente una influencia de los esclavos africanos (Waisman 2018: 193).

La meticulosidad del análisis musical contrasta con los silencios en la edición de partituras, asunto también neurálgico para la práctica y el debate musical actual. Causan curiosidad los fragmentos de la partitura Beatus Vir de Domenico Zipoli por sus diferencias con la versión publicada años antes (Waisman 2018: 254). En Historia de la música en España e Hispanoamérica esta pieza fue transcrita en compás de 4 / 4 y en la obra que tenemos entre manos está en compás 2/4. Además, en el libro español la partitura tiene una línea de violín que aquí fue excluida a partir del compás número 309 (Waisman 2018: 254 figura 10-1). ¿En qué radican tales diferencias? ¿Un descuido en la diagramación del libro? o ¿una revisión de la primera transcripción? Habría sido de gran utilidad para músicos intérpretes incluir una reflexión acerca de la transcripción del repertorio colonial específicamente, mencionando quizás las decisiones a las que un editor se enfrenta y anexando una lista de partituras publicadas en notación moderna.

Por otra parte, como heredero de la musicología tradicional y particularmente de la vertiente fundada por Robert Stevenson, Waisman otorga cierta centralidad a la figura del compositor. Sin criticar su pertinencia, llama la atención que se recurra a expresiones algo grandilocuentes sin justificarlas para referirse a algunos compositores ${ }^{7}$. Este no fue el caso de Gaspar Fernández cuyas obras fueron analizadas meticulosamente y su habilidad compositiva quedó bien sustentada. Incluso, parece

7 Por ejemplo, “[...] sin duda la [música] más importante es la de Hernando Franco, Gutierre Fernández Hidalgo y Pedro Bermúdez (Waisman 2018: 52)” o “[ ... l los dos mayores compositores [de Puebla]”, refiriéndose a Francisco López Capillas y Antonio de Salazar (Waisman 2018: 151). 
que la profundidad de este análisis estuvo motivada por el debate académico. En las entrelíneas, el autor dialoga al respecto con textos de Robert Snow (1990) y Omar Morales Abril (2013), quienes consideran que este compositor era "limitado" en la composición polifónica ${ }^{8}$. Desde otra perspectiva también sería interesante explicar cuáles compositores fueron reconocidos por sus contemporáneos e intentar buscar un porqué. Esto nos hablaría más de la escala de valores de aquel tiempo, que de la de musicólogos actuales.

\section{IV}

La obra aquí comentada lleva a pensar en su relación con la historiografía centrada en la actividad musical europea, durante los mismos tres siglos. Este trabajo resulta ser un caso híbrido muy interesante, pues al mismo tiempo que parece defender la autonomía e individualidad del caso hispanoamericano, también parece inclinado a usar coordenadas implícitas en la historiografía europea para valorar algunos elementos. Hay que reconocer que la historiografía centrada en ciertas figuras y aspectos de la actividad musical europea fue potente e influyó la forma de escribir otras historias musicales, ya sea imitando o contestando algunos de sus postulados.

En primer lugar, la publicación de Waisman parece compartir afectos con las historias de la música europea tradicionales. La figura del compositor -a la que ya me referí- y la música polifónica estarían en la cumbre de una escala de valores en común. En el caso que nos ocupa, todo indica que la presencia de música polifónica en los diversos contextos y momentos es usada como un indicador positivo de desarrollo musical ${ }^{9}$. ¿Hasta qué punto la valoración de la polifonía es una proyección de nuestro tiempo o de una corriente estética en particular? O, ¿`su alta estimación también estaba vigente en la sociedad colonial? De ser así, ¿qué sectores de la sociedad daban muestras de esta predilección? Quizás el uso de polifonía en los ritos principales de la Iglesia sea una muestra de la importancia que se le adjudicaba. Sin embargo, sabemos que la música usada en ese contexto tenía importancia, justamente, por su ligación con el culto y con la conservación de la tradición y del poder simbólico. ¿Quiénes la valoraban estéticamente? O ¿quiénes la oían como producto de la destreza en una técnica compleja? Son preguntas que deja la lectura del libro.

En segundo lugar, también existe tensión en la narrativa de Waisman con las historias de la música eurocentristas. El autor reconoce que son relatos parciales con ínfulas de universalidad y que nomenclaturas instauradas por esa historiografía no son aplicables directamente a la música del período colonial ${ }^{10}$. Sin embargo, es desafortunado el poco desarrollo de fragmentos confusos, que dan la impresión de querer demostrar o refutar algo de la tradición europea. Por ejemplo, el enunciado "Si Gaspar Fernández o Juan de Araujo no hubieran escrito música, nada habría cambiado en las obras de Mozart y Beethoven (Waisman 2018: 175)", deja más preguntas respecto del pensamiento historiográfico del autor que acerca de la hipótesis levantada. También encontramos afirmaciones arriesgadas como referirse a Juan de Herrera (-1738) en términos de "universalmente apreciado como compositor y músico (Waisman 2018: 269)". Si el adverbio "universalmente" fue usado en la época faltó mencionar la fuente y si no lo fue, la frase termina replicando los delirios de grandeza de la historiografía nacionalista de la que el autor dijo distanciarse en la introducción.

8 Waisman 2018: 201, nota 39. Las referencias bibliográficas de Snow y de Morales se detallan en el libro de Waisman y se omiten en la bibliografía final del presente documento.

9 "Sin hablar de decadencia, es notable [...] que no haya una sola expresión que permita suponer una práctica de música polifónica (Waisman 2018: 115-116)”. Esta afirmación abre la posibilidad de que, si existieran indicios de tal práctica, la actividad musical a la que se refiere esta reflexión, gozaría de mayor importancia.

10 Es el caso del término "barroco", dosificado para describir casos puntuales de la música hispanoamericana. Ver Waisman 2018: 175, 280-288. 
Todo trabajo de musicología con perspectiva histórica se depara con la división básica de su carácter bidisciplinario. En el caso de la obra de Waisman, se optó por separar los temas propiamente históricos y musicales. Cada una de las tres partes principales comienza con un capítulo pertinente al contexto histórico y enseguida vienen los capítulos histórico-musicales. Tal organización es frecuente en trabajos de ciencias humanas que consideran que, la sola exposición del contexto explica la relación entre él y el objeto de estudio, pero no siempre sucede así. En el libro comentado, por ejemplo, sería imperioso relacionar la práctica de reclutar niños de la élite indígena para la enseñanza musical en el siglo XVIII -ya mencionada -, con la caída demográfica indígena y el alto grado de mestizaje expuestos en el capítulo de contexto de este período (Waisman 2018: 243). Además de que el término "nobleza indígena" merecería ser ponderado regionalmente, queda la pregunta: con tal cambio en la población indígena ¿dónde sobrevivió, y dónde no, una "nobleza indígena" capaz de seguir alimentando las plazas de músicos aprendices?

Quizás sea más exacto plantear que el conocimiento social, cultural, económico, político e intelectual del investigador en relación con determinada época es, básicamente, una herramienta analítica. Después, en la construcción de su narrativa histórica, dicho contexto será pertinente si se enlaza con la temática o problema principal. En este sentido, las menciones a repertorio europeo en lenguas amerindias, hechas por Waisman, invitan a preguntar si tales piezas musicales guardaron relación con la política lingüística de la Colonia, un aspecto menos musical y más contextual. Inclusive, para comprender las posibles implicaciones que este repertorio tuvo en su época, sería iluminador dirigir el foco a la diversidad de lenguas existente en América y las dificultades que esto ocasionó a los colonizadores. Escribir la letra de una melodía en uno de los idiomas hablados en América implicó, primero, vencer los prejuicios de quienes no los consideraban sistemas capaces de comunicar los principios de la fe cristiana, y, en segundo lugar, demandó su estudio lingǘístico y adecuación al alfabeto latino para representarlo sobre el papel ${ }^{11}$. ¿Hasta qué punto la política de "lenguas generales" de Felipe II, que impuso algunas lenguas indígenas a regiones específicas como idiomas de colonización y ordenó escribir gramáticas, puede explicar la aparición de composiciones en determinadas lenguas amerindias? Como fue expuesto por John Gaddis, una de las habilidades del historiador es saber alternar en su narrativa entre planos focalizados (objeto de estudio) y panorámicos (contexto), a la manera de un cineasta (Gaddis 2003).

Si bien es verdad que la obra se enriquece con trabajos ya clásicos de la historiografía colonial como los de James Lockhart (1992) y Serge Gruzinski (1991), y con conceptos en boga como "agencia indígena (Waisman 2018: 84, 88)", hay momentos en que complejidades de la época obligarían a optar por una escritura más matizada. Esto sucede, en particular, con aspectos socioeconómicos ${ }^{12}$. Para la historiografía musical, sería útil definir cuidadosamente las categorías "semiprofesional" y "profesional", usadas al señalar la existencia de "capillas musicales indígenas semiprofesionales" y la "aparición de una clase de músico profesional indígena" en Cuzco en los siglos XVII y XVIII (Waisman 2018: 120, 125). Al parecer, la profesionalización es entendida en relación con la existencia de un salario. Pues, más adelante, refiriéndose a las misiones en Paraguay donde los músicos

11 Como sabemos, la mayoría de las lenguas indígenas eran ágrafas y, aquellas que desarrollaron sistemas de escritura -tema polémico entre especialistas-, lo hicieron en sistemas diferentes al fonográfico segmental del español, donde cada signo representa un fonema. Ver González de Pérez 2004.

12 Por ejemplo, cifras demográficas aportadas por historiadores como Marcello Carmagnani resultan más confiables que las usadas por Richard Konetzke en 1972, reproducidas por Waisman. Los estudios demográficos han avanzado y revisado sus métodos. Como explicó Carmagnani, los datos tomados de registros parroquiales no son solo categorías étnicas, "puede[n] ser también de carácter social, o no reflejar otra cosa que una simple realidad de conciencia subjetiva (Carmagnani 1972: 426)". Llevando en consideración cuidados metodológicos y diversas discusiones, él mismo propuso datos porcentuales para el continente en 2004, sin que estos puedan ser tratados como definitivos. Ver Carmagnani 2004: 81, 83. 
no tenían sueldo, se aclara que, en su caso, "no podemos hablar de una corporación de músicos profesionales (Waisman 2018: 130)”.

Aunque la remuneración salarial sea uno de los criterios usados por la sociología para identificar la profesionalización de un oficio, es problemático llevar tal parámetro a la sociedad colonial cuando existían economías mixtas, como, incluso, es señalado por el mismo autor (Waisman 2018: 125). Una zambullida en los trabajos del historiador Ruggiero Romano, por ejemplo, alertaría de la paupérrima circulación monetaria durante el período, a pesar de la alta extracción de metales preciosos. Aun en grandes centros mineros, la moneda metálica no circuló en el conjunto de la sociedad, existiendo amplias zonas de autoconsumo y trueque (Romano 1998). Considerando las complejidades de la vida económica colonial donde la monetarización incipiente coexistía con la institucionalización del trabajo forzado y la esclavitud, habría que problematizar la noción de salario, pues ella se torna insuficiente para hablar de profesionalización musical ${ }^{13}$.

Por otro lado, el autor avisa en la introducción que el libro se basa en fuentes secundarias, es decir, en publicaciones de investigadores que han trabajado con los documentos coloniales -como inventarios, crónicas, partituras, actas de cabildo, relatos de viajeros, cartas anuas, etc.-. No obstante, el texto se nutre repetidas veces con citas directas a esos documentos, también consultados por el autor, enriqueciendo la narrativa.

El trabajo gana profundidad cuando hace crítica de fuentes, ejercicio propio del quehacer histórico. Por ejemplo, acertadamente se advierte que los sacerdotes que escribieron música en las misiones tenían motivos particulares para exagerar la calidad de esta actividad, o que, incluso, escribían influenciados por la novela de caballería y por los relatos hagiográficos con obligatorias escenas milagrosas (Waisman 2018: 75-76). El libro también es acertado al profundizar en el caso de la obra de fray Antonio de Remesal, Historia general de las Indias Occidentales y particular de la gobernación de Chiapa y Guatemala (1619), que ofrece datos históricamente imprecisos, lo que -por cierto- es usual en las crónicas coloniales (Waisman 2018: 75).

El manejo de fuentes primarias demanda un constante ejercicio de hermenéutica, el que hizo falta en otros momentos. A título de ejemplo, me permito detenerme en una cita del padre jesuita José de Acosta para clarificar los matices que arroja una posible forma de hacer tal crítica. El autor retoma la mención hecha por Acosta al uso de un "modo de canto" indígena para difundir la fe católica y de "composiciones y tonadas" europeas cantadas en lenguas indígenas. En seguida Waisman le atribuye al jesuita haber identificado dos estilos en la música catequística en general, el indio y el español (Waisman 2018: 80). Más allá de tal interpretación, interesa señalar que la observación del padre Acosta no era una descripción desinteresada, sino, por el contrario, un postulado que reforzaba un argumento profundamente político de su libro Historia natural y moral de las Indias (1590).

El padre José de Acosta fue un intelectual español importante en su época. Estuvo en el Virreinato del Perú entre 1572 y 1586 . Allí fue fundador de las misiones jesuitas, rector del Colegio Jesuita de Lima, provincial de la Compañía de Jesús y participó en el III Concilio Limense, donde se organizó la doctrina y política de evangelización indígena. Su experiencia en América y su envolvimiento político lo llevaron a escribir después en España el libro Historia natural y moral de las Indias (1590) para incorporar al continente americano en el orden antiguo. En su libro, Acosta fue incisivo en demostrar que el hombre del Nuevo Mundo era un ente espiritual dotado de razón y de alma. Para Acosta, el alma indígena justificaba su evangelización y su racionalidad lo hacía capaz de vivir bajo un gobierno fundamentado en la religión cristiana (Acosta 2006). Existiendo sectores de la sociedad colonial que consideraban "faltos de entendimiento" a los indígenas, Acosta aprovechó el apartado en el que se refirió a la música para reafirmar su humanidad racional: "Ningún linaje de hombres que vivan en común, se ha descubierto que no tenga su modo de entretenimiento y recreación (Acosta 2006: 354)". En seguida pasó a mencionar los diversos bailes, romances y juegos indígenas, entre cuyos detalles está la cita usada por Waisman.

Dentro de la lógica de José de Acosta, la correlación entre melodías indígenas con textos católicos y composiciones europeas en lengua indígena ayudaba a demostrar la racionalidad del hombre americano. En realidad, poco interesaba especificar en qué lugar del continente se daba esa práctica, pues la

13 Raúl Torres (2015) se interesó por la situación laboral de los músicos de la catedral de México en la segunda mitad del siglo XVIII, mapeando la diversidad de retribuciones, beneficios y tipos de pagos que podían tener como funcionarios de la catedral. 
veracidad del hecho no era tan valiosa como su poder argumentativo. Incluso este no necesariamente fue observado (o mejor, escuchado) directamente por el jesuita. Sabemos que el padre Acosta escribió su libro basado en sus vivencias en el Virreinato del Perú y que sus datos sobre el Virreinato de la Nueva España los copió de escritos de otros autores que conoció en su paso por México, de regreso a España (O'Gorman 2006: XVII-XXXI ). Solo un trabajo comparativo con sus fuentes nos ayudaría a saber si pudo ser testigo o no de tal práctica e intentar especificar el lugar en que se dio. Pero, por ahora, lo que interesa señalar es que la mención tomada por Waisman trasciende a discusiones y preocupaciones de la época que solo son identificables tras un ejercicio de crítica de fuentes. Si bien es cierto que las palabras de Acosta continúan siendo útiles para acercarnos a las posibles prácticas musicales en la catequesis, su contextualización expone uno de los lugares otorgados a la música en un debate tan importante como la inclusión del Nuevo Mundo en el orden antiguo.

Un comentario final. Escribir una historia, en singular, requiere formular una pregunta, o un conjunto de preguntas, y construir una narrativa articulada que las responda. Este ejercicio podría basarse en datos disponibles en estudios anteriores o en informaciones nuevas. Sea usando una u otra vía -o ambas-, sabemos que cualquier tiempo pretérito no deja de ser fragmentario en el presente. Las reconstrucciones que hacemos dependen de indicios parciales y del tipo de preguntas que hagamos ${ }^{14}$. En consecuencia, la disciplina histórica invita a cuestionar constantemente el pasado y, partiendo de esas preguntas, encarrilar los hechos fragmentarios en respuestas hipotéticas. Paul Veyne (1984), citado por Waisman, nos recuerda que el historiador teje "tramas" con los hechos históricos y que cada trama se construye para responder preguntas de su tiempo.

En última instancia, ¿cuál fue el propósito de escribir un libro como el aquí comentado? Me parece que la reedición de dos de sus terceras partes con la adición de nuevos datos pudo obedecer a un impulso ancestral, historiográficamente hablando, de buscar reunir todos los indicios del pasado en un mismo lugar. Esta quimera me recuerda el cuento "Del rigor en la ciencia" de Jorge Luis Borges, acerca de un imperio donde los cartógrafos hicieron un mapa tan grande como el propio imperio. Sin desconocer que es fundamental reunir el mayor número de datos para construir nuestras interpretaciones del pasado, me parece que las informaciones incorporadas no innovaron las "tramas", pues, básicamente, persistieron las mismas preguntas.

Con todo, la-recopilación y organización de información realizadas en la obra de Waisman facilita la formulación de preguntas de amplio alcance geográfico o temporal. Sería interesante que trabajos futuros les hicieran seguimientos más acuciosos a fenómenos transversales, considerando que las políticas e instituciones implantadas a lo largo y ancho del dominio español justifican, contextualmente hablando, estudios comparativos. Ejemplo de ello podrían ser, 1) las negociaciones entre los cabildos eclesiásticos y los contextos musicales locales, contrastando lo que sucedía en ciudades centrales para el imperio y ciudades con importancia regional. 2) El tránsito de repertorio escrito y compositores por el territorio, apuntado por Waisman, ameritaría preguntarse por los canales de comunicación, redes personales y su fluidez en diversos momentos del período. 3) Las variables económicas atrás de la actividad musical catedralicia en diferentes lugares y momentos revelarían aspectos desconocidos de la propia economía colonial. En relación con ámbitos musicales fuera de las paredes de las catedrales, la curiosidad es aun mayor, debido a los silencios de la documentación. El lugar social del músico mestizo a principios de la Colonia y al final, tras tres siglos de mezcla interracial; el nivel de representatividad y variaciones geográficas de los escasos indicios de música instrumental; las consecuencias del empleo de esclavos e indígenas músicos en la conformación del repertorio de tradición oral de los siglos siguientes; y un largo etcétera que los investigadores especialistas podrán sugerir a partir de la lectura del trabajo de Waisman.

14 Historiadores como Carlo Ginzburg y Jacques Le Goff, entre otros, se refirieron a estos asuntos a finales de la década de 1970. Ver Le Goff 1990 y Ginzburg 1989. 


\section{BIBLIOGRAFÍA}

Acosta, JosEPH DE

2006 Historia natural y moral de las Indias . 3a edición. México: Fondo de Cultura Económica.

Albino, Ramiro

2016 Música colonial hispanoamericana. Córdoba: [edición independiente].

Carmagnani, Marcello

1972 "Demografía y sociedad: la estructura social de los centros mineros del norte de México, 1600-1720”, Historia Mexicana, 83, pp. 419-459.

2004 El otro occidente. América latina desde la invasión europea hasta la globalización. México: El Colegio de México.

GADDIS, John Lewis

2003 Paisagens da história. Como os historiadores mapeiam o passado. Rio de Janeiro: Campus.

Ginzburg, Carlo

1989 Mitos, emblemas, sinais: morfologia e história. São Paulo: Companhia das Letras.

González de Pérez, María Stella

2004 "Hacia una reflexión sobre la escritura en América precolombina", Thesaurus, LVI (enerodiciembre), pp. 1-43.

Le GofF, JacQues

1990 Historia e memória. Campinas: Editora da Unicamp.

MARÍN López, JAVIER

2018 "Introducción. Intercambios musicales en el mundo atlántico: un paradigma en construcción". Músicas coloniales a debate. Procesos de intercambio euroamericanos. Javier Marín López (editor). Madrid: Instituto Complutense de Ciencias Musicales, pp. 17-22.

O'Gorman, EDMUndo

2006 "Prólogo". Historia natural y moral de las Indias, Joseph de Acosta (autor). México: Fondo de Cultura Económica, pp. XVII-LXV.

Romano, Ruggiero

1998 Moneda, seudomonedas y circulación monetaria en las economías de México. México: Fondo de Cultura Económica, El Colegio de México.

TORRES, RAÚL

2015 Los músicos de la catedral metropolitana de México (1750-1791). Transgresión o sumisión. México: Universidad Autónoma de la Ciudad de México.

Veyne, Paul

1984 Cómo se escribe la historia. Madrid: Editorial Alianza.

WAISMAN, LEONARDO

2004 "La América española: proyecto y resistencia". Políticas y prácticas musicales en el mundo de Felipe II. Estudios sobre la música en España, sus instituciones y sus territorios en la segunda mitad del siglo XVI, John Griffiths \& Javier Suárez Pajares (editores), Madrid: Instituto Complutense de Ciencias Musicales, pp. 503-550.

2014 "La música en la América española". Historia de la música en España e Hispanoamérica. La música en el siglo XVIII, José Máximo Leza (editor), Madrid: Fondo de Cultura Económica de España, pp. 556-652.

2018 Una historia de la música colonial hispanoamericana. Buenos Aires: Gourmet Musical Ediciones.

s//d Curriculum vitae. Academia.edu. https://conicet-ar.academia.edu/leonardowaisman/ CurriculumVitae [acceso: 9 de septiembre de 2019]. 